\title{
INTERNAL FLOW ANALYSIS OF LARGE LID SOLID ROCKET MOTORS
}

\author{
Brian A. Laubacher' \\ Cordant Technologies Inc., Thiokol Propulsion \\ Brigham City, Utah
}

\begin{abstract}
Traditionally, Solid Rocket Motor (SRM) internal ballistic performance has been analyzed and predicted with either zero-dimensional (volume filling) codes or one-dimensional ballistics codes. One dimensional simulation of SRM performance is only necessary for ignition modeling, or for motors that have large length to port diameter ratios which exhibit an axial "pressure drop" during the early burn times. This type of prediction works quite well for many types of motors, however, when motor aspect ratios get large, and port to throat ratios get closer to one, two dimensional effects can become significant.
\end{abstract}

The initial propellant grain configuration for the Space Shuttle Reusable Solid Rocket Motor (RSRM) was analyzed with 2-D, steady, axi-symmetric computational fluid dynamics (CFD). The results of the CFD analysis show that the steady-state performance prediction at the initial bum geometry, in general, agrees well with I-D transient prediction results at an early time, however, significant features of the 2-D flow are captured with the CFD results that would otherwise go unnoticed. Capturing these subtle differences gives a greater confidence to modeling accuracy, and additional insight with which to model secondary internal flow effects like erosive burning.

Detailed analysis of the 2-D flowfield has led to the discovery of its hidden 1-D isentropic behavior, and provided the means for a thorough and simplified understanding of internal solid rocket motor flow.

Performance parameters such as nozzle stagnation pressure, static pressure drop, characteristic velocity, thrust and specific impulse are discussed in detail and compared for different modeling and prediction methods. The predicted performance using both the 1 $D$ codes and the CFD results are compared with measured data obtained from static tests of the RSRM. The differences and limitations of predictions using 1 . $D$ and 2-D flow fjelds are discussed and some

- Senior Principal Engineer, ALAA Member

-2000 Thiokol Propulsion, a division of Cordant Technalogies, Inc. suggestions for the design of large L/D motors and more critically, motors with port to throat ratios near one, are covered.

\section{NOMENCLATURE}

$\begin{array}{ll}C_{P} & \text { Specific heat (joule/kg K) } \\ \gamma & \text { Ratio of Specific Heats } \\ \dot{m} & \text { Mass Flow Rate }(\mathrm{kg} / \mathrm{sec}) \\ \mathrm{P} & \text { Static Pressure }\left(\mathrm{N} / \mathrm{m}^{2}\right) \\ a & \text { Bum Rate Coefficient } \\ \mathrm{n} & \text { Bum Rate Exponent } \\ \vec{n} & \text { Unit Normal Vector of Cell Face } \\ n_{x} & \text { x-component of unit normal vector } \\ \mathrm{M} & \text { Mach Number } \\ \mathrm{A} & \text { Area (m²) } \\ x, y, z & \text { Orthogonal coordinates } \\ \vec{V} & \text { Velocity Vector }(\mathrm{m} / \mathrm{sec}) \\ \mathrm{u}, \mathrm{v}, \mathrm{w} & \text { Gas velocity components }\left(\mathrm{m}^{2} / \mathrm{sec}\right) \\ \rho & \text { Gas density }\left(\mathrm{kg} / \mathrm{m}^{3}\right) \\ \rho_{s} & \text { Propellant solid density }\left(\mathrm{kg} / \mathrm{m}^{3}\right) \\ & \text { Gas viscosity }\left(\mathrm{N} \quad \mathrm{sec} / \mathrm{m}^{2}\right)\end{array}$

\section{INTRODUCTION}

The Space Shuttle Reusable Solid Rocket Motor (RSRM) initial propellant grain configuration, upon ignition. creates an axial static pressure drop which is the result of a combination of geometrical and physical features, including high $L / D(\approx 44)$ length to bore or port diameter ratio, mass addition along the bore, low port area to throat area ratio $(\approx 1.15)$, flow restrictions, etc. Historically in the shuttle motor program, this pressure drop has been estimated by using external case strain gauge measurements from static test motors as well as predictions from I-D (one-dimensional) ballistics codes. Reasonably good agreement was obtained in the past when the two methods were correlated. but a consistent discrepancy was noted in the pressure drop for early burn times primarily in the aft segment. Since pressure data (measured directly and/or deduced from secondary measurements) is the 
most readily quantifiable internal motor parameter, matching this pressure field is a valuable anchor for all internal motor simulations.

With the use of 2-D (two-dimensional) computational fluid dynamics (CFD), a more detailed look into the initial flowfield of the RSRM is possible, and the differences between the pressures computed from strain gauge measurements and the I-D ballistics codes like the Solid Propellant Rocket Motor Performance Program (SPP') can be identified and accounted for. As these differences are explained, a thorough examination of the internal motor flowfield is presented with a detailed comparison of the 2-D CFD results and how they relate to the basic concepts from 1-D isentropic flow. New insights into the internal motor flowfield and associated interactions are gained through study of the more representative 2-D CFD simulations. Additional influences of turbulence are discussed as well. Finally, the RSRM baseline CFD model is validated with static test measurements.

\section{RSRM 1-D MODEL RESULTS}

The one-dimensional flow results for the RSRM, at approximately 1.0 seconds into burn from the Thiokol code $(\mathrm{SCB} 02)^{2}$ as well as the results from the SPP are compared with the steady-state CFD results in Figure 6. The 1-D codes do a very good job of matching the full duration performance of the RSRM, however, at early burn times, when the motor port area and the port/throat ratio are smallest, the 2-D effects within the flow are not captured. It is clear that the predicted static pressure drop early in burn, is underestimated by the 1-D codes when the tapered aft segment is encountered. This was similar to what was reported by Clayton ${ }^{3}$. SPP version 6 has corrections that attempt to account for compressibility and convergence losses, but they do not capture the effect of the taper for a motor with this $L / D$ and port/throat ratio.

The bias between the RSRM aft end static pressure as computed from the I-D codes and the static pressure reconstructed from strain gauge data has been observed in the past ${ }^{4,5}$, and with the use of CFD, can be identified and explained.

\section{CFDANALYSIS \\ RSRM CFD MODEL DESCRIPTION}

The baseline RSRM CFD model was created for use with the SHARP code. SHARPB is a fully-coupled, finite-volume, Navier-Stokes solver that was developed by $\operatorname{Loh}^{6,7,8}$ at Thiokol. SHARP@ is capable of solving 1-D, 2-D, and 3-D geometries under both steady-state and transient assumptions. The code is constructed in order to include the effects of turbulence, multi-phases, and multiple-species, however, only the $\mathrm{k}$ - turbulence modeling was included for this model.

The baseline model consisted of the RSRM initial grain configuration geometry modeled as 2-D axisymmetric. The structured mesh consisted of 8 blocks, totaling 68,713 cells. The motor port and nozzle were represented by a block consisting of 1193 cells in the axial direction and 50 cells in the radial direction. The 3-D star grain in the forward segment was modeled as a cylinder of 35 inch radius with the mass flux augmented to account for the proper propellant surface area. The propellant grain shape included effects of vertical storage loads. The propellant boundaries were modeled as inlets with the mass flux computed by

$$
\begin{gathered}
\text { Equation } 1 \\
\frac{\dot{m}}{A}=\rho_{v} \cdot a P^{n}
\end{gathered}
$$

where the left hand side represent the mass flux, and the two terms on the right hand side consists of solid propellant density and propellant burn rate, respectively. The burn rate is computed as a function of the local static pressure. The burn rate coefficient " $a$ " was calculated using the RSRM nominal burn rate of $0.368 \mathrm{in} / \mathrm{sec}$, and a reference pressure of 625 psia at 60 degrees $F$. The burn rate pressure exponent was 0.35 . The nozzle walls and other inert surfaces in the model were considered to be adiabatic, and the supersonic flow out of the nozzle utilized an extrapolation boundary condition. This type of dynamic boundary condition for the mass flux inlets adds slightly to the convergence time, but is the best method to properly model the propellant boundaries.

The model assumed that fully developed flow has been obtained within the motor cavity, however, no propellant grain regression has occurred. This assumption is conservative, and will reasonably model the motor performance at the onset of steady-state operation: approximately 1.0 second into burn.

The CFD model assumed that the fluid was a singlephase, chemically-frozen, calorically-perfect gas. The single phase assumption implies that the fluid is a homogenous gas and particle mixture with an equivalent molecular weight 
The turbulence model used was the standard $k-$. The mass injection boundaries have a $5 \%$ turbulent intensity specified along with an initial turbulent viscosity ratio (TVR) of 100 . During the development of the CFD model, it was noticed that the turbulence level had a significant effect on the flow solution. Large magnitudes of turbulent viscosity and intensity were observed within the flowfield that lead to unrealistic motor pressure levels. The internal bore flowfield Reynolds number (approximately $3.0^{*} 10^{7}$ ) was off the scale with respect to the three turbulent regimes described by Beddini'. In order to restrict the turbulence level generated by the models and match the RSRM static test data, the model was "tuned" by limiting the maximum TVR.

\section{RSRM CFD MODEL RESULTS}

The results from the CFD model of the RSRM are compared with data measurements and 1-D performance predictions in Figure 6 . The static pressure drop predicted down the motor was known to be 165 psi from the static test measurements ${ }^{4}$, and was achieved with the CFD model by adjusting the maximum ratio of turbulent to molecular viscosity to 10,000 . Adjusting this ratio had a large influence on the radial velocity profile, particularly in the aft segment of the motor, and consequently on motor static pressure. A comparison of the effects of different levels of TVR can be seen in the velocity profiles in the aft segment (Figures 1-3) as well as the influence on static pressure and Mach number (Figures 4 and 5). The higher turbulent viscosity levels tended to dampen out the velocity gradients, which in turn lowered the centerline Mach numbers and raised the static pressure, similar to the I-D results. The damping out of velocity gradient allowed the grain taper in the aft segment to be "felt", consequently inducing the static pressure recovery. The lowest levels of turbulent viscosity produced the highest centerline Mach numbers and lowest static pressure levels. "Tuning" the model by this method produced a static pressure drop match with the test data of 165 psi. With the proper static pressure drop matched, the resulting motor headend pressure was 906 psi. This headend pressure was only 8 psi below the target nominal RSRM headend pressure of 914 psi or within $1.0 \%$.

\section{RSRM CFD MODEL VERIFICATION}

The CFD based RSRM pressure prediction (at nominal conditions) was compared with the static test data as seen in Figure 6 . The data included pressure calculated from strain gauges from RSRM qualification motors QM-7 and QM-8 as well as measured pressure from two HPM design static test motors TEM-6 and TEM-7. The differences in design between RSRM and HPM have been assumed to have only a small impact on the pressure drop and is verified by the agreement of the test data.

The dotted lines in Figure 6 show "scaled" nominal performing CFD results which had bias' imposed in order to show a more direct comparison with the predicted pressures from the static test data. No adjustments have been made to the static test data of TEM motors which are shown at delivered test conditions. Also, the pressure deduced from strain for QM-7 and QM-8 were at delivered conditions. The method for obtaining the pressures is described by Gruet $^{4}$ and Salita ${ }^{5}$

The motor pressure drop as calculated from the headend pressure and boot cavity pressure on the TEM motors indicated that the pressure drop was 165 psi. Also, Gruet ${ }^{4}$ documents the pressure drop for the QM7 and QM-8 motors to be the same. The CFD results match that drop very well. The shape of the pressure drop can be compared with the pressure extracted from strain gauge data from $Q M-7$ and $Q M-8$. The match with the QM-7 data is quite good, however, the cold motor results from QM-8 do not match the pressure drop as well. It was postulated by Gruet that the difference in shape of the pressure drop may be due to the PMBT (Propellant Mean Bulk Temperature). The propellant temperature would effect the propellant modulus and deformation, and consequently could influence the strain gauge measurements.

\section{MODEL BALLISTIC PARAMETER COMPARISON}

While the local differences between the CFD model and I-D model seem large, the integrated results comparison is much closer. Table 1 shows some of the performance parameters computed via the 2 different models.

The calculation of mass flow rate, thrust, and specific impulse for the CFD results were done according to Equations 2 through 4.

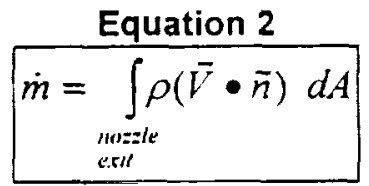

Equation 3

$$
F_{\mathrm{r}}=\int_{\substack{n \in z=z c \\ \text { exti }}}\left(\dot{m} * u+\mathrm{P} * \mathrm{n}_{\mathrm{v}}\right) d .4
$$




$$
\begin{aligned}
& \text { Equation } 4 \\
& I s p=\frac{F_{x}}{\dot{m}}
\end{aligned}
$$

Calculating the nozzle stagnation pressure from the CFD results required an integration of total pressure across the nozzle throat region. The integration was computed with a mass weighted average. The mass weighted average consisted of a summation of the product of total pressure and mass flow rate for each cell and then dividing by total mass flow rate.

\begin{tabular}{|l|l|l|l|}
\hline & $\begin{array}{l}\text { CFD results } \\
\text { SPP }\end{array}$ & $\begin{array}{l}\text { Results } \\
\text { Ballistics } \\
\text { (SCB02) }\end{array}$ \\
\hline Thrust (lbf) & $3,157,000$ & $3,180,200$ & $3,171,400$ \\
\hline $\begin{array}{l}\text { Mass flow Rate } \\
\text { (lbm/sec) }\end{array}$ & 11,810 & 11,850 & 11,828 \\
\hline Isp (lbf sechbm) & 267.30 & 268.40 & 268.12 \\
\hline $\begin{array}{l}\text { Nozzle Stagnation } \\
\text { Pressure (psia) }\end{array}$ & $\begin{array}{l}820.8 \text { (mass } \\
\text { weighted avg) }\end{array}$ & 814.5 & 816.0 \\
\hline $\begin{array}{l}\text { Headend Pressure } \\
\text { (psia) }\end{array}$ & 906 & 905 & 910 \\
\hline $\begin{array}{l}\text { Axial Static } \\
\text { Pressure Drop } \\
\text { (psi) }\end{array}$ & 165 & 103 & 112 \\
\hline $\begin{array}{l}\text { Axial Total } \\
\text { Pressure Loss (psi) }\end{array}$ & 85 & 90 & 94 \\
\hline
\end{tabular}

Table I Performance Parameter Comparison (1.0 seconds into burn)

\section{FLOWFIELD OBSERVATIONS: STATIC PRESSURE, TOTAL PRESSURE, AND MACH NUMBER}

Seen in figures 7-10, are the streamlines, static pressure, total pressure, and Mach number distributions for the results from the RSRM CFD model. It is clear in the figures that the static pressure gradient is primarily axial, and that very little radial gradient exists. However, for the total pressure, there is a significant radial gradient. And for the Mach number, both radial and axial gradients are present.

Looking closely at the static pressure, the absence of any significant radial gradient implies that the flow is generally in the axial direction. This also means that the static pressure along the propellant walls is approximately the same as the static pressure along the motor centerline. Further. close examination of the contours of total pressure show that it very closely resembles the streamlines. This implies that the flow is nearly isentropic along the streamlines. It is also known that the gas injection velocity at the propellant boundaries is small, on the order of $3 \mathrm{~m} / \mathrm{s}$. With these facts in mind, some interesting observations can be made which greatly simplify the understanding of the flowfield.

Isentropic flow relationships for pressure ratio and area ratio as a function of Mach number are shown in Equations 5 and 6.

\section{Equation 5}

$\frac{P_{0}}{P}=\left(1+\frac{\gamma-1}{2} \cdot M^{2}\right)^{\left(\frac{\gamma}{\gamma-1}\right)}$

\section{Equation 6}

$$
\left(\frac{A}{A^{*}}\right)^{2}=\frac{1}{M^{2}}\left[\frac{2}{\gamma+1}\left(1+\frac{\gamma-1}{2} M^{2}\right)\right]^{\frac{\gamma+1}{\gamma-1}}
$$

The observed flow behavior from CFD is consistent with the equations. The flow entering from the propellant boundaries enters with a static pressure that is very similar to the static pressure along the centerline of the motor at the same axial position. Also, since the propellant gas flow enters with a relatively low velocity and Mach number, the total pressure and static pressure are essentially the same at the propellant boundaries. Therefore, the total pressure distribution along the propellant boundary is approximately the same as the static pressure distribution along the centerline. The total pressure along the motor centerline. though, is essentially constant since it is a streamline which emanates from the motor headend.

The flow area of the headend streamline or streamtube (formed by rotating adjacent streamlines around the axis of symmetry), is altered by many physical and aerodynamic features, consisting of the motor geometry, mass addition along the bore, flow from propellant slots, and also by the converging and diverging nozzle walls. The sonic area of a streamtube is defined by its minimum area which generally occurs at the nozzle throat. At any axial station in the motor then, the streamtube cross-sectional area and its corresponding sonic area provides the ratio with which to determine the pressure ratio ( $\mathrm{P} / \mathrm{PO})$ and Mach number from equations 5 and 6 . Figures 11 and 12 are comparison plots of pressure ratio and area ratio versus Mach number between an arbitrary headend streamline and isentropic flow results. The similarity verifies that even with turbulence and viscous forces, that the CFD computed streamtubes behave very closely to isentropic pipe flow. This means that as gas enters from the buming propellant walls, each 
streamtube behaves like 1-D isentropic pipe flow. The streamtube cross sectional area (concentric ring shaped) changes, the static pressure and Mach number adjust accordingly, but the total pressure remains the same. This was observed by King ${ }^{10}$, and shown again by Traineau et al. " for flow in a nozzleless motor, and is applicable to the RSRM and any other motor. The conclusion of these observations is that the motor static pressure drop is basically defined by the shape of the headend streamtube.

Two hypothetical situations can be looked at to further explain the above. Consider two cases for two different shape motor designs. For a motor with a large port to throat ratio, it is reasonably straightforward that the headend streamtube would gradually converge, and then right in the vicinity of the nozzle, a significant "streamline compression" would result (see Figure 13). This compression would not necessarily be the result of mass addition as much as just an overall change in flow area caused by the nozzle convergence. This means that just upstream of the throat (and all the way to the motor headend), that the ratio of local streamtube flow area to its sonic flow area would be large and consequently the Mach numbers would be low and the static pressure would be very near the total pressure. Therefore, very little static pressure drop would exist in the motor cavity. This would be the case for a "bulb" shaped motor (large chamber, small throat) or even the RSRM in a late-in-bum configuration.

The second situation is a motor design with a large $\mathrm{L} / \mathrm{D}$ ratio and small port/hroat ratio. The early-burn grain designs for the RSRM falls into this category. These motors have port to throat ratios that are closer to I.0, and as a result, the headend streamlines compress early on, and by the time the flow has traveled to the aft end of the motor, the compression and mass addition process is nearly complete. Upon entrance to the nozzle throat, very little further "geometrical" streamline compression occurs. Therefore, the streamtube area is just slightly higher than the sonic flow area, resulting in much higher Mach numbers in the aft end of the motor. Along that headend streamline then, the higher aft end Mach numbers result in lower static pressures and consequently, a larger motor static pressure drop is obtained. Again, the key to the motor static pressure drop then is the shape of the headend streamtube and it is the contribution of mass addition down the bore along with the motor port and nozzle flow area that define its shape.

\section{ADDITIONAL ISSUES}

In l-D codes, the term nozzle stagnation pressure refers to one value of total pressure at the nozzle. In the I-D codes, total pressure along the motor bore incurs "losses" in order to arrive at the nozzle with a lower value than the headend pressure. However, in the 2-D results from CFD, the fact that the nozzle stagnation pressure is lower than the motor headend pressure is not necessarily due to "losses" as much as its interpretation as a simple dilution process. As the static pressure decreases down the motor bore, the mass injected, at that same axial position, possesses a total pressure similar in magnitude to the centerline static pressure. The gradual addition of mass with lower total pressure then becomes the mechanism for the so-called loss.

\section{EFFECT OF SLOTS}

The local static pressure drops that occur near the propellant slots for the RSRM and other large L/D ratio segmented motors can be explained by the induced streamline compression for the motor centerline streamlines. These streamlines are compressed by the geometrical influence of the propellant overhang condition and also by the slot mass addition. The effect is a sudden change in area ratio for the streamtube which results in the observed change in static pressure.

\section{EFFECT OF PROPELLANT BORE TAPER}

The lack of pressure recovery in the RSRM aft segment grain taper is slightly more difficult to explain. In this case, the bore flow detaches from the wall boundaries and assumes its own aerodynamic shape. This shape is such that grain taper is almost unnoticed. The headend streamtube does not respond or "feel" the bore area divergence, and maintains an almost constant flow area. I-D codes however must respond to the increase in flow area caused by the tapered grain. The I-D codes may invoke a Culick ${ }^{12}$ profile to the flow as is done in SPP, but that is not enough to reduce the pressure recovery.

\section{EFFECT OF MOTOR SIZE}

Large L/D ratio for a solid rocket motor does not necessarily mean large pressure drop. If the RSRM had a 2 -inch radius throat, the overall chamber pressure would be quite high, but the motor pressure drop and velocities would be very small. In that case, the $L / D$ ratio remains unchanged but the port/throat ratio is significantly higher. On the other hand, a motor with an $L / D$ of 3 or so could exhibit a very large pressure drop if the port/throat ratio were near 1.0, and there was sufficient surface mass flux to cause choking. With a port/throat ratio near $\mathrm{I}$, the aft end of 
the motor will experience the high Mach numbers and lower static pressure associated with the sonic condition. It is clear from this analogy that the port/hroat ratio has the most influence on motor pressure drop. In other words, if the nozzle does not induce much in the way of a streamline compression, the streamline sonic area is only slightly exceeded for the aft end of the motor. Equation 5 can be arranged to show that the maximum motor pressure drop will be:

$$
\begin{gathered}
\text { Equation 7 } \\
\frac{P_{0}-P}{P_{0}}=1-\left[\frac{\gamma+1}{2}\right]^{\frac{-\gamma}{\gamma-1}}
\end{gathered}
$$

\section{MOTOR PERFORMANCE IMPACT}

The overall impact to the predicted or reconstructed RSRM motor performance based on the differences between 1-D and 2-D CFD is minimized by the fact that these identified pressure differences affect only a fraction of the motor, and for only a small duration of motor operation. A 50 psi lower aft segment pressure will decrease the propellant burn rate in the aft segment from $0.401 \mathrm{in} / \mathrm{sec}$ to $0.392 \mathrm{in} / \mathrm{sec}$, but shortly thereafter, as the propellant bore diameter increases and port/throat ratio increases during burn, the 2-D effects and pressure bias between the 1-D and 2-D CFD results would disappear. The pressure bias would have a minimal effect on the 1-D reconstructed burn rate as well. Assuming that the bias existed for 20 seconds of the 123 seconds of motor operation, and linearly ramped to no difference at that time, the aft segment time-average static pressure would only decrease by approximately 5 psi. This decrease in average pressure would result in an increase to the aft segment reconstructed burn rate of approximately $0.001 \mathrm{in} / \mathrm{sec}$, and the overall motor reconstructed burn rate difference would be roughly $1 / 4$ of that, which is well within the $0.005 \mathrm{in} / \mathrm{sec}$ historical 3-sigma variation. The lower aft segment static pressure would reduce the initial propellant mass flow rate by only 33 $\mathrm{lbm} / \mathrm{sec}$ out of $11,800 \mathrm{lbm} / \mathrm{sec}$. Again, this difference would wash out after approximately 20 seconds.

\section{TURBULENCE MODELING COMMENTS}

One complication to the simplified approach of flowfield analysis presented above is the influence of turbulence modeling. The presence of turbulence affects the streamlines and velocity gradients within the flow. Fortunately, including turbulence in the CFD models doesn't necessarily invalidate the previous discussions of the isentropic flow relationships. The presence of turbulence basically alters the shape of the streamlines by smearing out regions of high velocity gradients and the corresponding eddies that would be generated. The CFD analyses in this document are steady-state, consequently the inherently unsteady behavior of turbulent eddies must be eliminated by artificially increasing the viscosity of the fluid in these regions. The end-item of the turbulence model is to determine a turbulent viscosity at each point in the flowfield. This turbulent viscosity can be several thousand times higher than the molecular viscosity of the fluid. While TVR magnitudes in the thousands appear to create a physically unrealistic condition, it is necessary in some regions of the motor in order to be able to capture the net effect of the highly turbulent regions without having to model the small-scale unsteady reality of the flowfield.

\section{EROSIVE BURNING}

It is well known that the main ingredient for erosive burning is high speed motor bore flow. While the extent of erosive burning in the RSRM is not known, it is commonly believed that it is quite small. Motors designed with a low port/throat ratio though increase the propensity for erosive burning because of the higher bore velocities. This design feature should be kept in mind if the propellant is susceptible to erosive burning.

\section{CONCLUSIONS}

One dimensional ballistics codes have been used for many years to accurately predict and reconstruct the performance of solid rockets. Recent CFD work performed on the RSRM model to baseline the flowfield of the initial motor port configuration has shown a slight difference in the results between I-D and 2-D CFD predicted motor static pressure drops. The pressure drop difference was consistent with a bias seen in past analyses done by Gruet ${ }^{4}$ and Salita, and was shown to be caused by aft segment grain taper which was consistent with the findings of Clayton ${ }^{3}$ Anchoring the CFD results against measured pressures and pressures deduced from static test strain gauge measurements, verified the model accuracy. The subsequent flowfield investigation resulted in an analogy relating the complex $2-\mathrm{D}$ internal flow to simple 1-D isentropic pipe flow. The various influences of pressure drop, e.g. mass addition, bore and nozzle geometry, have been shown to affect the headend streamline of the motor, and dictate the motor pressure drop. The importance of motor port design and the critical influence of the portthroat ratio in determining the motor pressure drop have been identified. Finally, motors with port/hroat ratios below 1.2 may be candidates for showing a difference 
between pressure drops computed between I-D and 2D codes.

\section{ACKNOWLEDGEMENTS}

The Author wishes to thank Mr. Mark Eagar of United Technologies, Chemical Systems Division, and also Professor Robert A. Beddini, from the University of Illinois for their comments and helpful suggestions. Additionally, Mr. Robert Morstadt, and Mr. Fred Perkins were very helpful in preparing this paper. And thanks to Dr. Qunzhen Wang for his maintenance of the SHARP® code.

\section{REFERENCES}

1 "The Solid Propellant Rocket Motor Performance Prediction computer Program (SPP)", Software and Engineering Associates, Inc, Carson City Nevada

2 "A User's Guide for Computer Program No. SCB02

An Internal Ballistics Program for Segmented Solid Propellant Rocket Motors", Thiokol Propulsion, 1982

${ }^{3}$ Clayton, C. D., "Flow Fields in Solid Rocket Motors with Tapered Bores", AIAA Paper 96-2643.

${ }^{4}$ Gruet, L. "QM-7 And QM-8 Transient Axial Pressure Calculated From Strain Gauge Data", TWR-63695, Thiokol Corporation, 30 March 1992

s Salita, M. "Verification of Spatial and Temporal Pressure Distributions in Segmented Solid Rocket Motors", AIAA Paper 89-0298.
${ }^{6}$ Loh, H.T. and Golafshani, M., "Computation of Viscous Chemically Reacting Flows in Hybrid Rocket Motors Using an Upwind LU-SSOR Scheme," AIAA paper 90-1570.

Loh, H.T., Smith-Kent, R., Perkins, F., and Chwalowski, P. 1996 "Evaluation Of Aft Skirt Length Effects On Rocket Motor Base Heat Using Computational Fluid Dynamics," AIAA paper 962645.

${ }^{8}$ Loh, H. T., Chwalowski, P. "One and Two-Phase Converging Diverging Nozzle Flow Study", AIAA Paper 95-0084.

${ }^{9}$ Beddini, R. A., "Injection-Induced Flows in PorousWalled Ducts", AIAA Journal, Vol. 24 No. 11, Nov. 1986, pp. 1766-1773

${ }^{10}$ King, M. K. "Consideration of Two-Dimensional Flow Effects on Nozzleless Rocket Performance", AIAA paper 84-1313

11 Traineau, J-C., Hervat, P., Kuentzmann, P., "ColdFlow Simulation of a Two-Dimensional Nozzleless Solid Rocket Motor", AIAA Paper 86-1447

12 Culick, F. E. C., "Rotational Axisymmetric Mean flow and Damping of Acoustic Waves in a Solid Propellant Rocket", AIAA Journal, Vol. 4, No. 8, 1966, pp. 1462-1464 


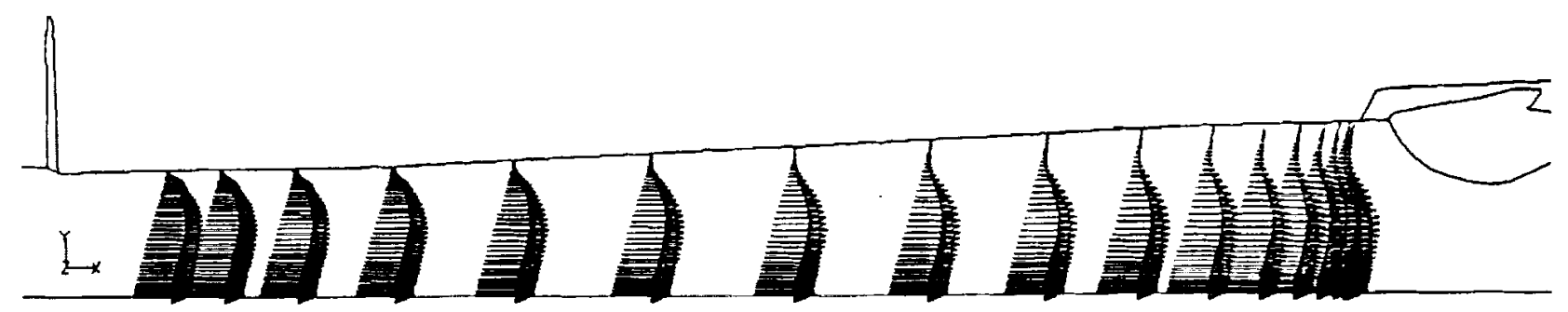

Figure 1 RSRM Aft Segment Velocity Vectors (low turbulent viscosity TVR=1,000)

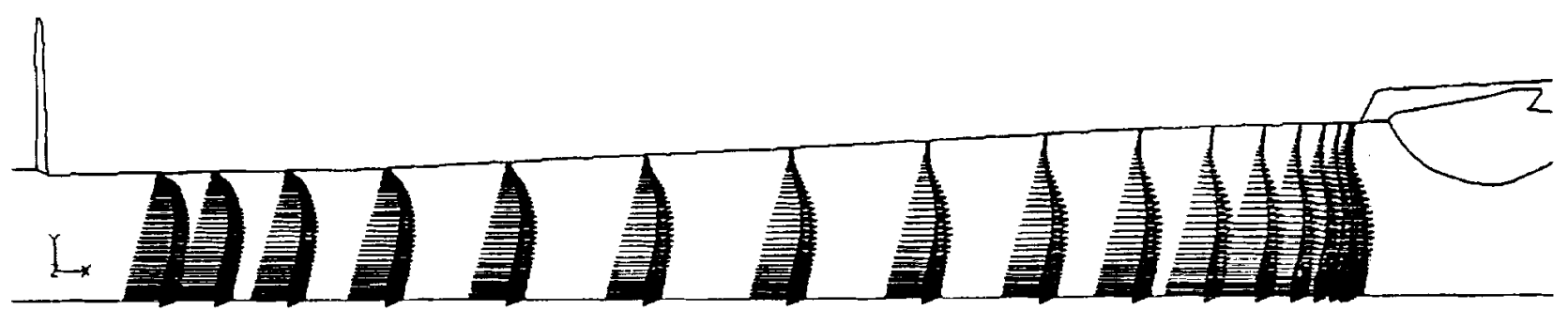

Figure 2 RSRM Aft Segment Velocity Vectors (correct turbulent viscosity TVR=10,000)

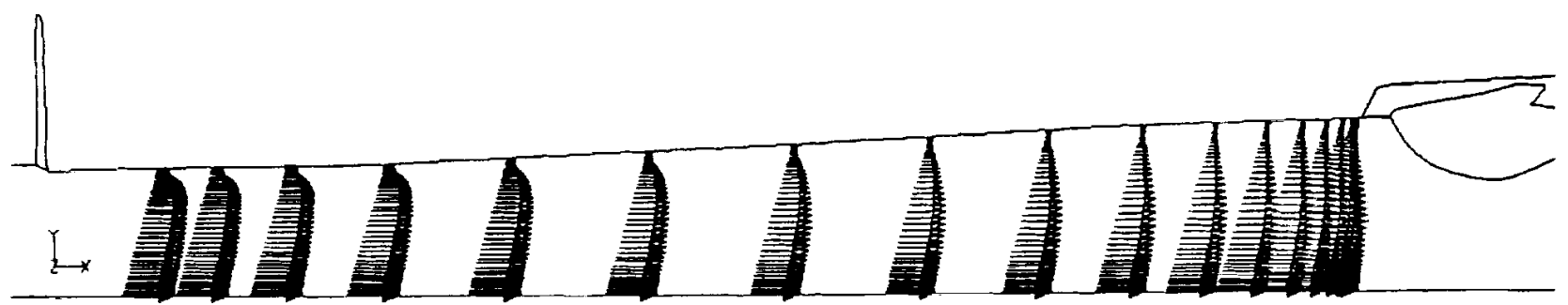

Figure 3 RSRM Aft Segment Velocity Vectors (high turbulent viscosity, $T V R=50,000$ ) 


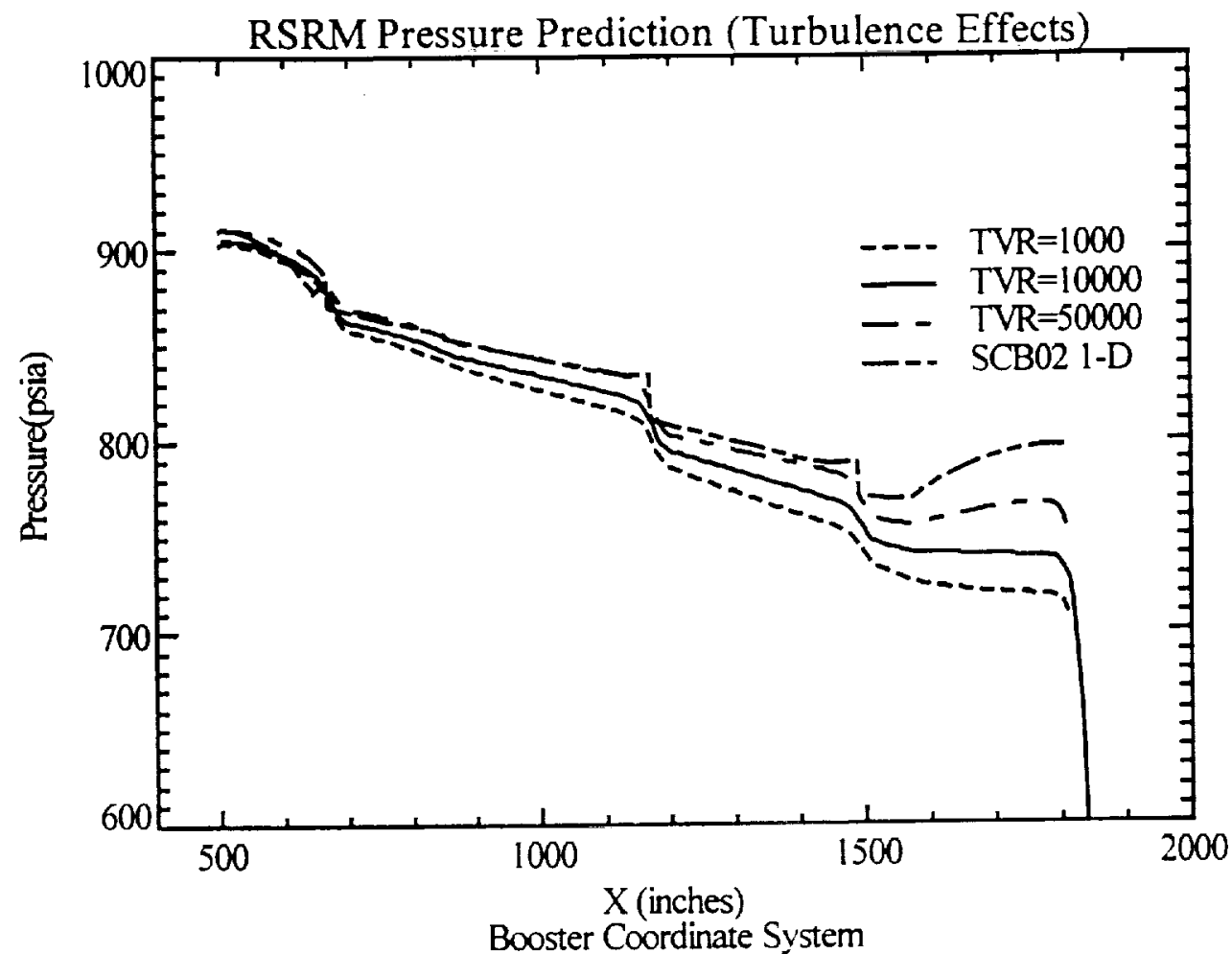

Figure 4 RSRM Pressure Prediction with Turbulence Effects

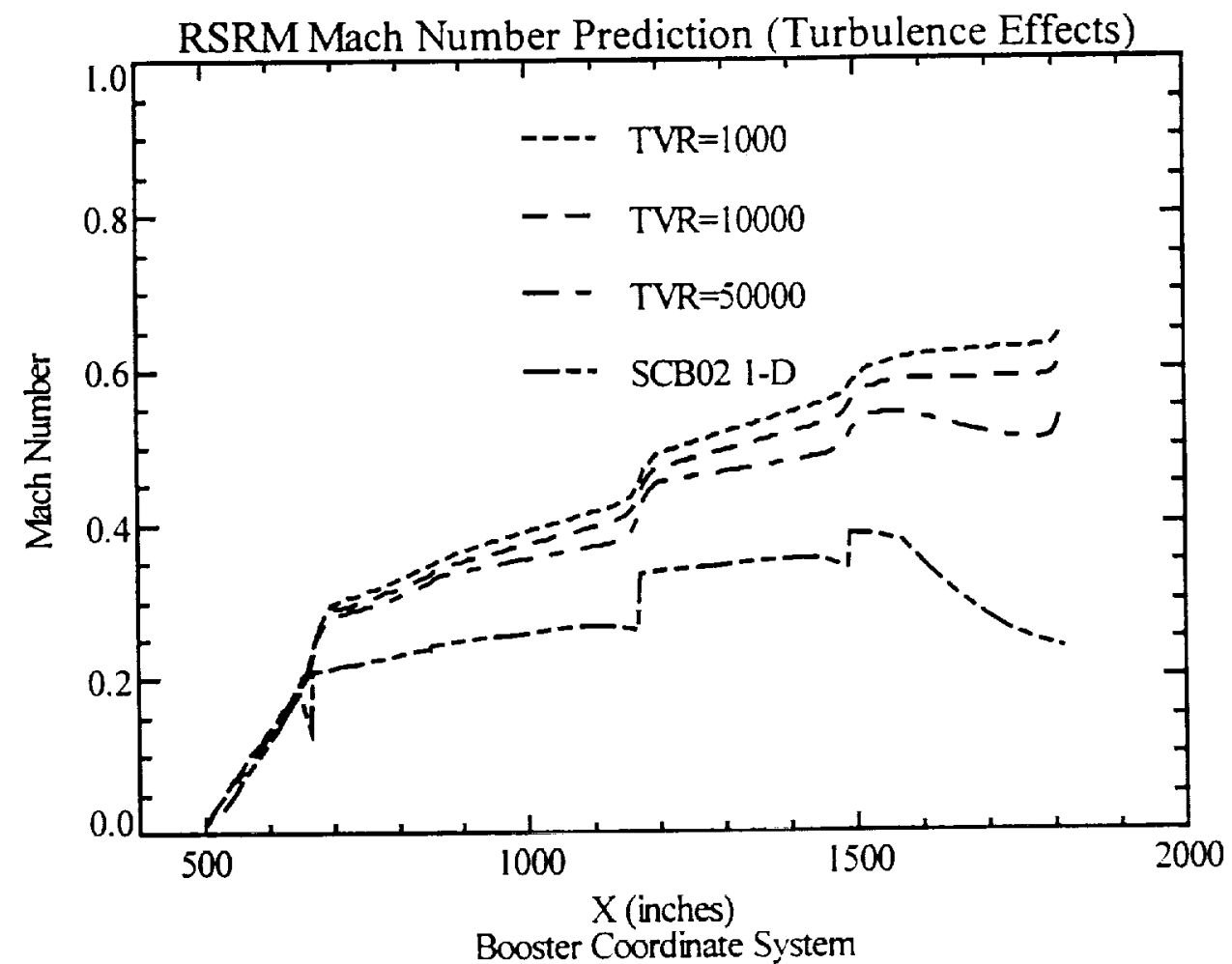

Figure 5 RSRM Mach Number with Turbulence Effects 


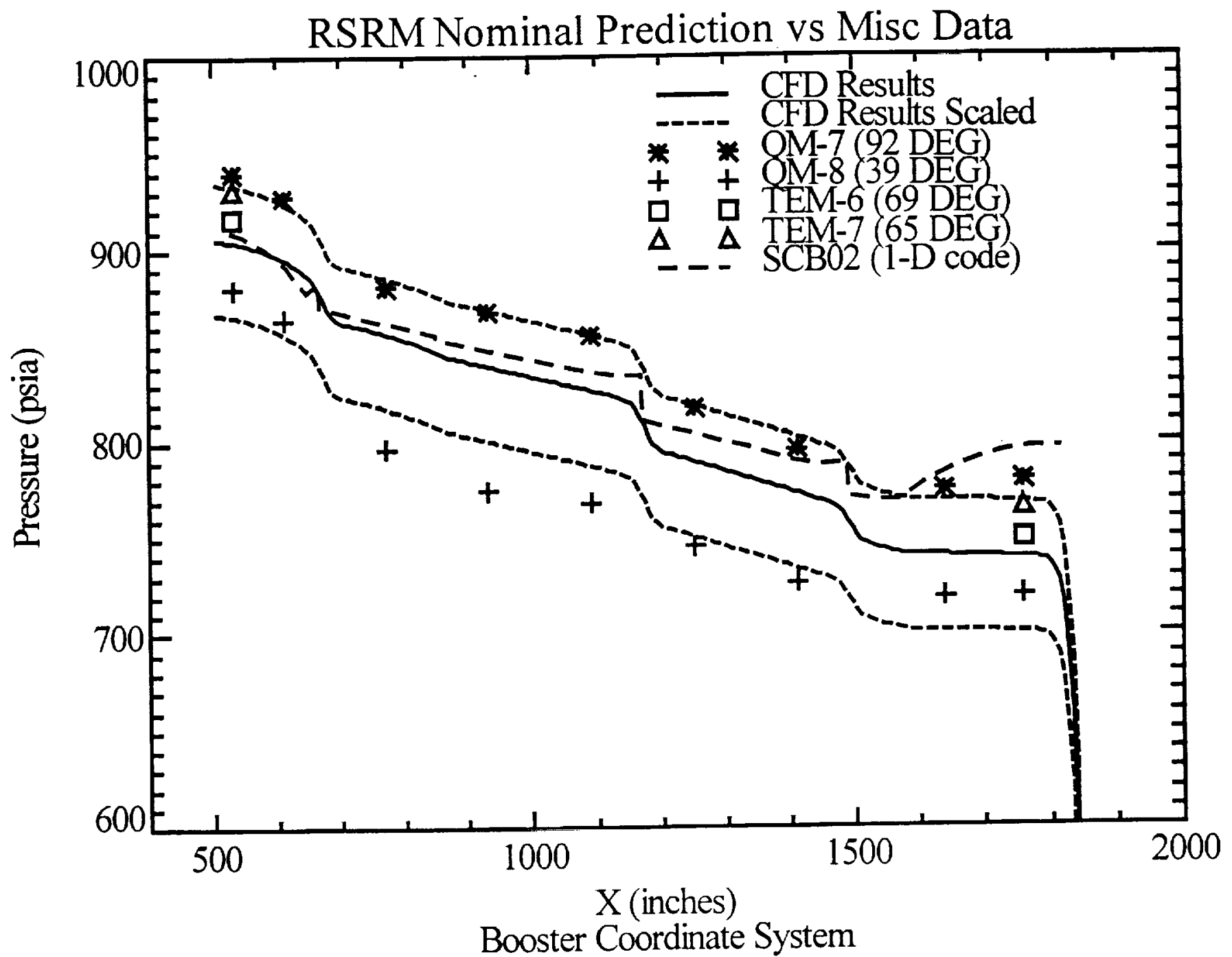

Figure 6 RSRM Baseline CFD Model Calibration (TVR=10,000) 


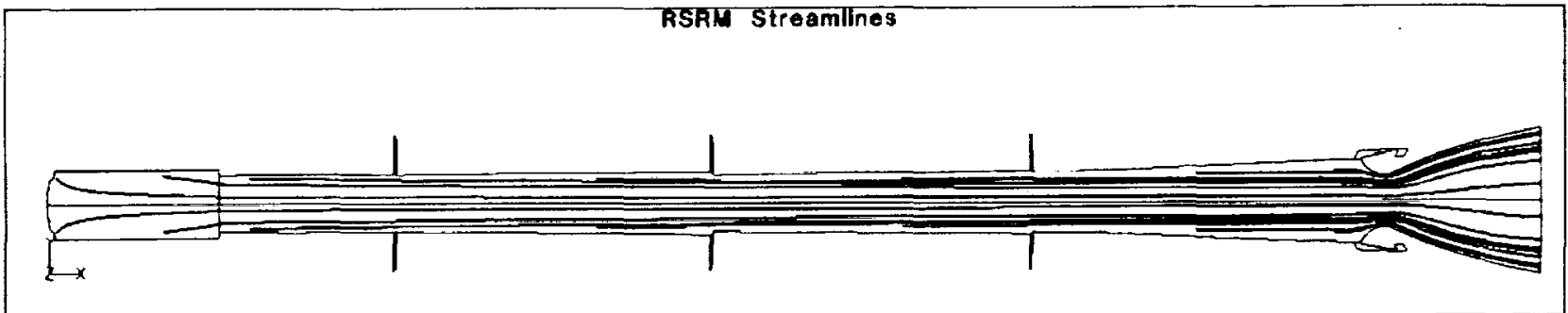

Figure 7 RSRM Streamlines

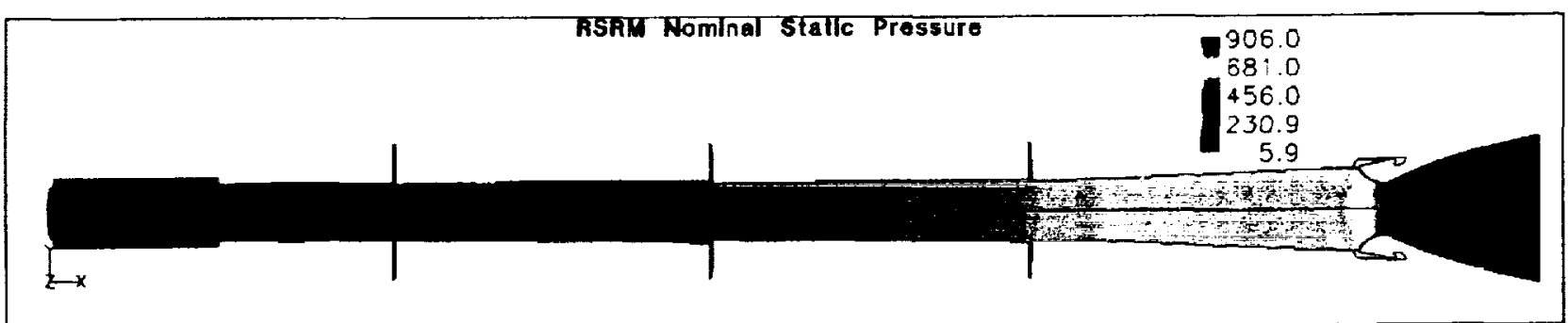

Figure 8 RSRM Static Pressure Contours

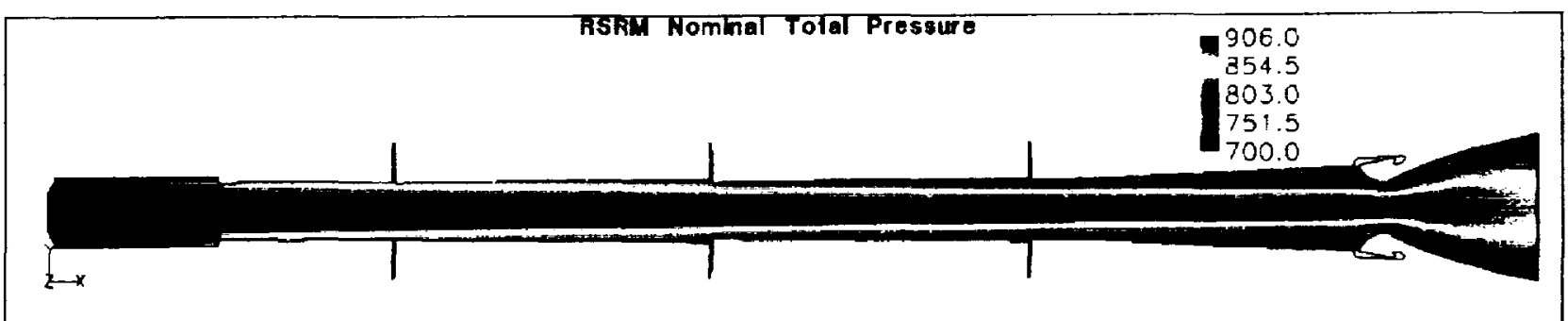

Figure 9 RSRM Total Pressure Contours

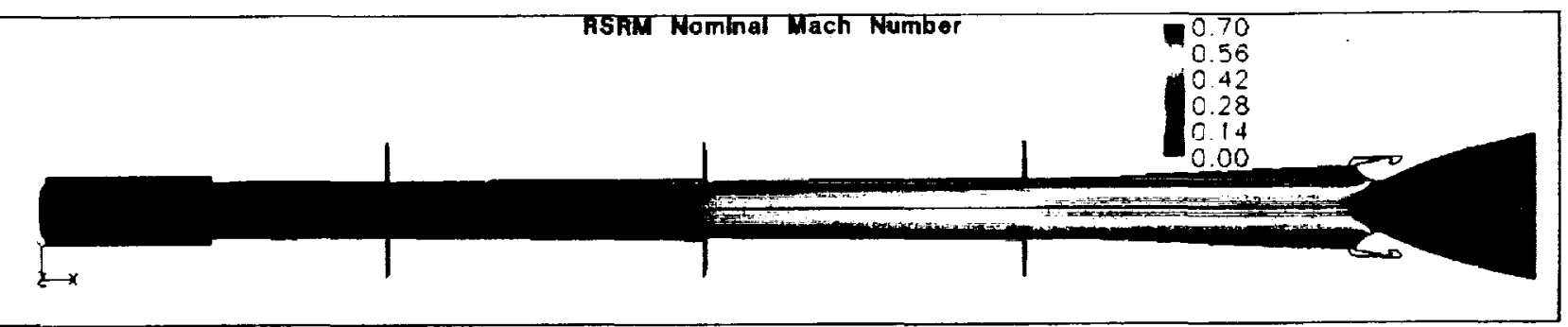

Figure 10 RSRM Mach Number Contours 


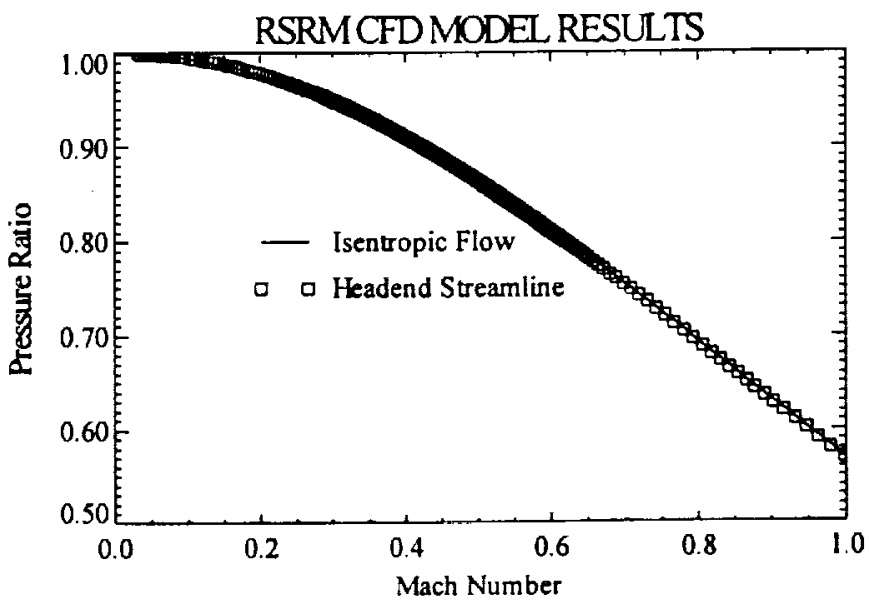

Figure 11 Pressure Ratio Versus Mach Number

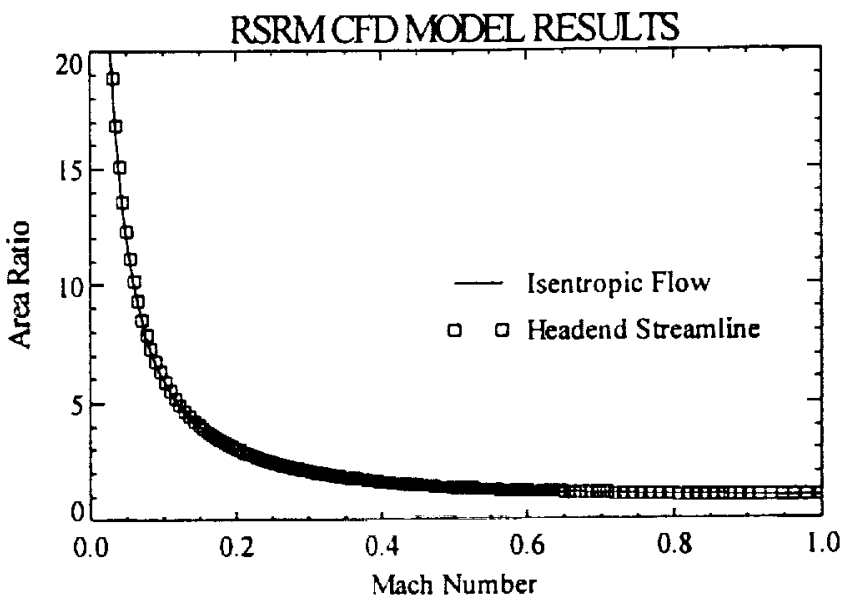

Figure 12 Area Ratio Versus Mach Number

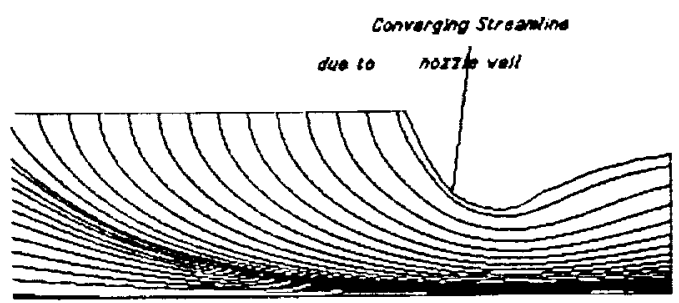

Figure 13 Example of Streamline Compression due to Geometrical Influences 